\title{
Substitution reactions between arenethiolate anions and 1,3-dihalo- 2,2-dimethylpropanes. Synthetic scope and mechanistic aspects
}

\author{
Cecilia A. Barrionuevo, Juan E. Argüello,* and Alicia B. Peñéñory* \\ Instituto de Investigaciones en Físico Química de Córdoba (INFIQC), \\ Departamento de Química Orgánica, Facultad de Ciencias Químicas, \\ Universidad Nacional de Córdoba, Córdoba 5000, Argentina \\ E-mail: jea@fcq.unc.edu.ar, penenory@fcq.unc.edu.ar
}

\section{Dedicated to Professors Rita H. de Rossi, Julio C. Podestá, Manuel González Sierra and Oscar S. Giordano}

\begin{abstract}
The synthetic scope of the reactions between benzenethiolate, 4-methoxybenzenethiolate, 2-naphthalenethiolate, and 2-pyridinethiolate anions with 1,3-dihalo-2,2-dimethylpropane was studied. These reactions render mono and disubstituted products from good to excellent yields. For all the substrates studied the monosubstituted halogenated product is the intermediate or the main product depending on the nature of the second leaving group. Aryl cyclopropyl sulfides were found as side products and their yields strongly depend on the base concentration (tertBuOK). Finally, using neopentyl iodide as a model, the mechanism of these reactions was evaluated based on non-kinetic evidence, demonstrating that the reactions switch from $\mathrm{S}_{\mathrm{RN}} 1$ to polar $\mathrm{S}_{\mathrm{N}} 2$ according to the solvent employed.
\end{abstract}

Keywords: Aliphatic substitution, $\mathrm{S}_{\mathrm{RN}} 1$, arenethiolate anions, neopentyl halides

\section{Introduction}

Aliphatic nucleophilic substitution can proceed through the classical polar $\mathrm{S}_{\mathrm{N}} 2, \mathrm{~S}_{\mathrm{N}} 1$, and related mechanisms, all of them visualized as the transfer of electrons by pairs. Electron transfer (ET) substitution reactions appear as an alternative for many systems which are low reactive or even unreactive through polar mechanisms. Their absence of reactivity is usually given by different structural factors, namely, strain (e.g., cycloalkyl and polycycloalkyl halides), steric (e.g., cycloalkyl, polycycloalkyl, and neopentyl halides); and electronic factors such as the presence of a perfluoroalkyl chain in aliphatic halides $\left(\mathrm{R}_{\mathrm{f}} \mathrm{X}\right)$. For these compounds, which can be substituted by ET, their radicals have to be formed by an initial ET as a single-electron-transfer (SET) 
process which can be reached by different means. The most commonly used include electrochemical initiation, thermal ET and photoinduced electron transfer (PET) from a charged nucleophile $\left(\mathrm{Nu}^{-}\right)$. Once the pairs of radicals are formed $(\mathrm{R} \bullet$ and $\mathrm{Nu} \bullet$ ), they can react in a cage reaction (Scheme 1, path a). However, the diffusion of the radical offers a new alternative where the addition of $\mathrm{R} \cdot$ to the $\mathrm{Nu}^{-}$triggers a $\mathrm{S}_{\mathrm{RN}} 1$ chain mechanism in which radical and radical anions are intermediates (Scheme 1, path b). Although these two possible pathways can be present, the $\mathrm{S}_{\mathrm{RN}} 1$ is the one which has been widely studied and shown to operate in most systems. ${ }^{1}$

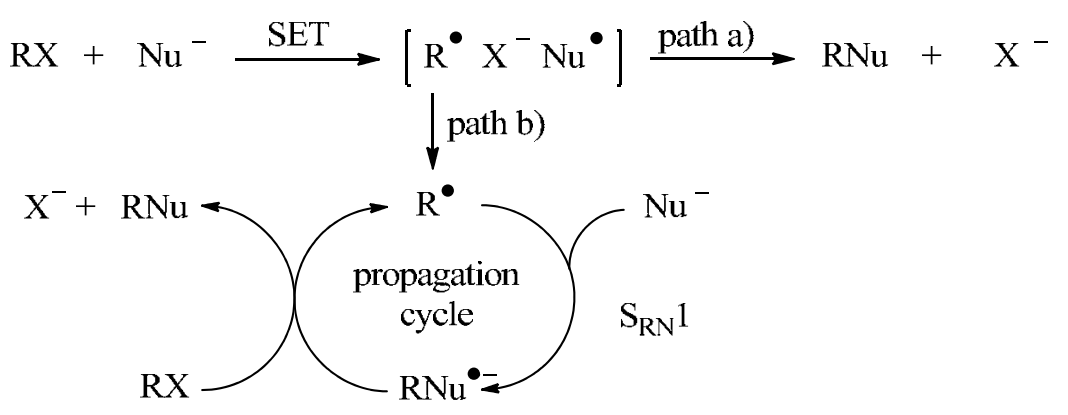

Scheme 1. General picture for electron transfer substitution reactions of aliphatic compounds.

For aliphatic halides with no low-lying $\pi^{*}$ orbital, a concerted dissociative ET approach is considered as an initiation step, where ET from the $\mathrm{Nu}^{-}$to substrate $\mathrm{RX}$ gives $\mathrm{R} \cdot$ and $\mathrm{X}^{-}$in a single step. A stepwise ET pathway involves another possibility through which the radical anion of the substrate is formed as an intermediate. This radical anion cleaves in a subsequent step. The $\mathrm{R} \cdot$ can react with the $\mathrm{Nu}^{-}$to give $\mathrm{RNu}^{-}$which, by ET to the substrate, forms the neutral substitution product and regenerates the intermediate radical needed to continue the propagation cycle (Scheme 1). The process affords, on the whole, a nucleophilic substitution. The mechanism has termination steps that depend on $\mathrm{RX}, \mathrm{Nu}^{-}$, and experimental conditions.

Inhibition by radical traps or radical anion scavengers has been extensively used to provide non-kinetic mechanistic evidence. The most commonly employed are di-tert-butylnitroxide (DTBN), 2,2,6,6-tetramethylpiperidine-1-oxyl (TEMPO), together with good electron acceptors such as $p$-dinitrobenzene ( $p$-DNB) or $m$-dinitrobenzene $\left(m\right.$-DNB). ${ }^{1}$

Neopentyl halides have been studied in ET substitution reactions because of their low reactivity in polar $\mathrm{S}_{\mathrm{N}} 1$ and $\mathrm{S}_{\mathrm{N}} 2$ mechanisms. Most of these studies have been carried out under irradiation in liquid ammonia as a solvent. In these reaction conditions, anions $\mathrm{PhS}^{-}, \mathrm{Ph}_{2} \mathrm{P}^{-}$, and $\mathrm{Ph}_{2} \mathrm{As}^{-}$react with neopentyl bromide giving 60,76 , and $82 \%$ yields of substitution, respectively (Equation 1). ${ }^{2}$ The rate constant for the reaction between a neopentyl radical and $\mathrm{Ph}_{2} \mathrm{P}^{-}$and $\mathrm{PhS}^{-}$ anions were found to be $1.3 \times 10^{9} \mathrm{M}^{-1} \mathrm{~s}^{-1}$ and $1.2 \times 10^{8} \mathrm{M}^{-1} \mathrm{~s}^{-1}$, respectively in $\mathrm{MeCN}$ as solvent, by using a neopentyl halide derivative containing a cyclizable probe of the 5-hexenyl type. ${ }^{3}$ 


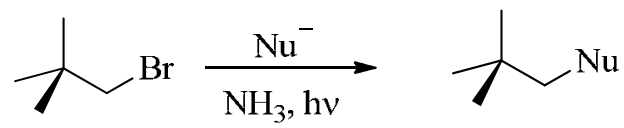

$$
\begin{aligned}
& \mathrm{Nu}^{-}=\mathrm{PhS}^{-}, \mathrm{Ph}_{2} \mathrm{P}^{-}, \mathrm{Ph}_{2} \mathrm{As}
\end{aligned}
$$

In contrast with the aromatic thiolate anion, $\mathrm{PhS}^{-}$, the aliphatic $i$-PrS ${ }^{-}$anion rendered quantitative straightforward substitution with 6-iodo-5,5-dimethyl-1-hexene as a probe. However, the same reaction, in the presence of dicyclohexylphosphine (DCHP), yielded up to $22 \%$ hydrocarbon products suggesting a SET mechanism for this anion. No evidence for this mechanistic pathway was observed with the bromide probe. ${ }^{4}$

The effects of leaving groups, solvent, and hydrogen atom donors have been investigated in the reaction of $\mathrm{BzCH}(\mathrm{Me})^{-}$with 6-X-5,5-dimethyl-1-hexenes (X $=\mathrm{I}, \mathrm{Br}$, or OTs) in HMPA. ${ }^{5}$ It is suggested that the reaction of the iodo derivative takes place in part with radicals as intermediates while the bromide and tosylate compounds appear to react via the $\mathrm{S}_{\mathrm{N}} 2$ pathway. ${ }^{5}$ Neopentyl iodide affords substitution with $\mathrm{BzCH}_{2}{ }^{-}$ions and with the anion of anthrone under irradiation in DMSO (65 and 52\%, respectively). Furthermore, substitution by the ${ }^{-} \mathrm{CH}_{2} \mathrm{NO}_{2}$ ion, which fails to photoinitiate the process, succeeds (69\%) under entrainment conditions (in the presence of $\mathrm{AcCH}_{2}{ }^{-}$ions); the $\mathrm{S}_{\mathrm{RN}} 1$ mechanism is proposed to account for these results. ${ }^{6}$

When the substrate has two leaving groups, disubstitution by the same $\mathrm{Nu}^{-}$is possible. The most studied aliphatic system bearing two leaving groups has been the gem-dihalocyclopropanes and dihalopolycycloalkanes. ${ }^{1 \mathrm{a}, \mathrm{b}}$ To the best of our knowledge there are just a few examples of this reaction in the neopentyl system. Thus, disubstituted (36\%) and monosubstituted reduced (16\%) compounds are obtained by reaction of 1,3-diiodo-2,2-dimethylpropane with $\mathrm{BzCH}_{2}{ }^{-}$ion in DMSO. ${ }^{6}$

1,3-Dihalo-2,2-dimethylpropanes $(\mathrm{X}=\mathrm{Br}$ and $\mathrm{Cl})$ have been used as starting material for the preparation of several cyclopropyl sulfides, sulfoxides and sulfones. ${ }^{7}$ Therefore, when 1,3dibromo-2,2-dimethylpropane is treated with $\mathrm{PhS}^{-}$(1 or 2 equiv) in refluxing ethanol, 3-bromo2,2-dimethylpropyl phenyl sulfide $(\mathrm{X}=\mathrm{Br}, 46 \%$ ) or 2,2-dimethyl-1,3-bis(phenylthio)propane (X $=\mathrm{PhS}, 74 \%$ ) are obtained after 15 or $52 \mathrm{~h}$, respectively. Following the same methodology up to $23 \%$ yield of 3-chloro-2,2-dimethylpropyl phenyl sulfide $(\mathrm{X}=\mathrm{Cl})$ can be prepared, starting from 1,3-dichloro-2,2-dimethylpropane under reflux for $20 \mathrm{~h}$ (Equation 2). ${ }^{7}$

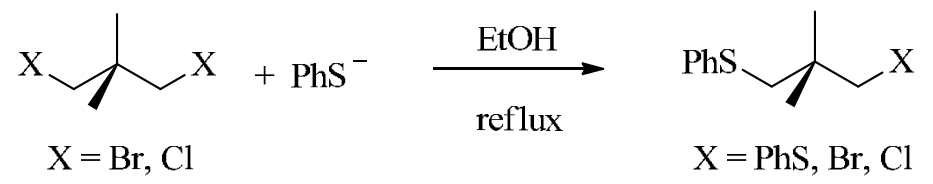

Cyclopropyl derivatives can be obtained in excellent yields by treatment of 3-halo-2,2dimethylpropyl phenyl sulfones with NaOEt in ethanol (Equation 3). Another approach consists in the use of the aryl (3-chloropropyl) sulfides, but strong basic conditions such as sodium amide in liquid ammonia are necessary for the formation of cyclopropane. ${ }^{8}$ 


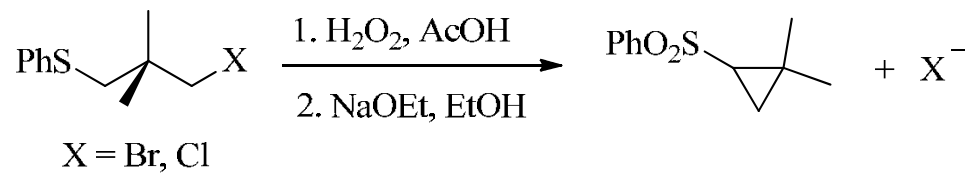

As stated before, it is difficult to perform nucleophilic substitution at C-1 and C-3 in the neopentyl system as 1,3-dihalo-2,2-dimethylpropane, and extreme reaction conditions are necessary (refluxing solvent and several reaction hours). We are interested in developing a methodology using arenethiolate anions in DMSO as solvent and under irradiation, in order to obtain the substitution products under mildest conditions. We will also consider the synthesis of the aryl cyclopropyl sulfides in a one-pot procedure by the addition of an extra amount of a strong base.

\section{Results and Discussion}

In an $\mathrm{S}_{\mathrm{RN}} 1$ reaction of neopentyl dihalides $\mathbf{1 b}-\mathbf{d}$ with arenethiolate anions $\mathbf{2 a - d}$, three possible reaction products can be found, namely, disubstituted 3, reduced monosubstituted 4 and monosubstituted with halogen retention (5, Y $=\mathrm{I} ; \mathbf{6}, \mathrm{Y}=\mathrm{Br} ; \mathbf{7}, \mathrm{Y}=\mathrm{Cl}$ ) derivatives (Equation 4). Compounds 3 and $\mathbf{4}$ are straightforwardly assigned to an intramolecular ET in the reaction mechanism, while products 5-7 are formed by ET from 5-7 radical anions to a molecule of substrate 1 (intermolecular ET). The product distributions depend on the nucleophile, the halogen and their space distribution in the substrate skeleton. ${ }^{9}$

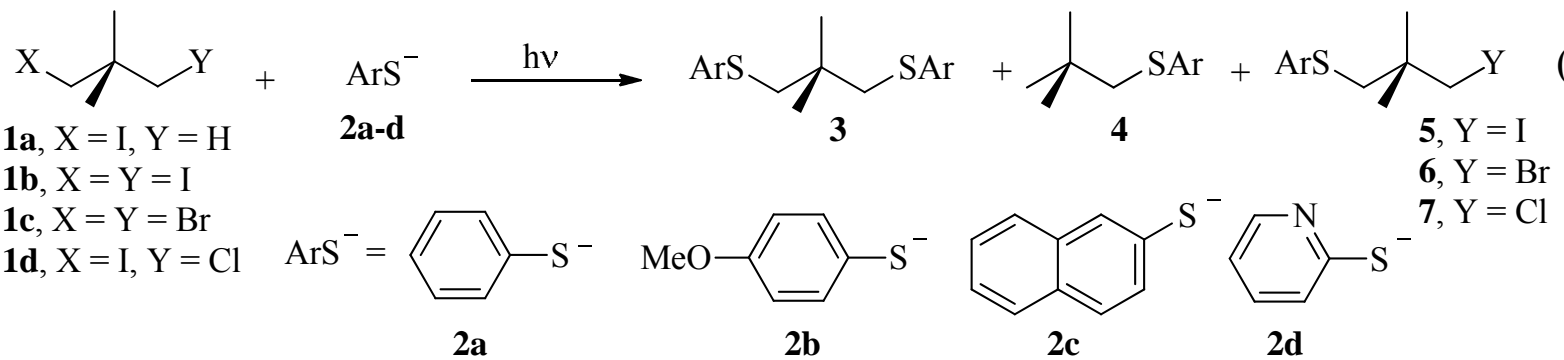

To explore the reaction between neopentyl halides with $\mathrm{ArS}^{-}$anions, four different substrates were chosen, 1-iodo-2,2-dimethylpropane 1a (neopentyl iodide), 1,3-diiodo-2,2dimethylpropane $\mathbf{1 b}$, 1,3-dibromo-2,2-dimethylpropane $\mathbf{1 c}$ and 1-chloro-3-iodo-2,2dimethylpropane 1d. The arenethiolate anions 2a-d were generated in situ by deprotonation using tert-BuOK and thiophenol, p-methoxythiophenol, 2-naphthalenethiol and 2-pyridinethiol, respectively. 


\section{Reactions of neopentyl iodide (1a), effect of the solvent and the additives}

Neopentyl bromide reacts with several nucleophiles by the $\mathrm{S}_{\mathrm{RN}} 1$ mechanism in different solvents such as liquid ammonia and $\mathrm{MeCN} .{ }^{2,3}$ However, the reactivity of the iodo derivative with $\mathrm{ArS}^{-}$ anions was not investigated yet. As such, the photoinduced reactions between neopentyl iodide and anions 2a-d were first studied. All the ArS ${ }^{-}$anions gave high yields of substitution products 4a-d after $1 \mathrm{~h}$ of reaction (Equation 5), benzenethiolate anion 2a was the most reactive giving the substitution product almost in quantitative yield (Table 1, entry 1). p-Methoxybenzenethiolate $\mathbf{2 b}$ and 2-naphthalenethiolate 2c anions had similar reactivity affording 83 and $86 \%$ yields of sulfides $\mathbf{4 b}$ and $\mathbf{4 c}$, respectively (Table 1, entries 2 and 3). Among the $\mathrm{ArS}^{-}$anions studied, 2pyridinethiolate anion $\mathbf{2 d}$ showed the less reactivity rendering product $\mathbf{4 d}$ in $68 \%$ yield (Table 1 , entry 4). This result can be ascribed to the further stabilization of anion $\mathbf{2 d}$ by delocalization of the negative charge on the electron-withdrawing group pyridine, lowering its reactivity.

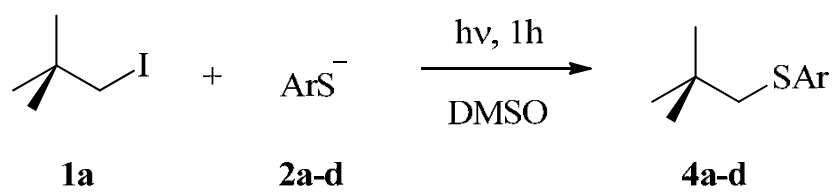

Table 1. Reactions of sulfur nucleophiles 2 with neopentyl iodide $1 \mathrm{a}$ in $\mathrm{DMSO}^{\mathrm{a}}$

\begin{tabular}{ccc}
\hline Entry & $\mathrm{Ar}^{-}$ & Product $(\%)^{\mathbf{b}}$ \\
\hline & $\mathrm{Ar}=$ & SAr \\
1 & 2a Ph & 4a 96 \\
2 & 2b $p-\mathrm{MeOC}_{6} \mathrm{H}_{4}$ & $\mathbf{4 b} 83$ \\
3 & 2c $2-\mathrm{C}_{10} \mathrm{H}_{7}$ & 4c 86 \\
4 & 2d $2-\mathrm{C}_{5} \mathrm{H}_{4} \mathrm{~N}$ & 4d 68 \\
\hline
\end{tabular}

${ }^{\mathrm{a}} \mathbf{1 a}=0.05 \mathrm{M} ; \mathrm{ArS}^{-}=0.25 \mathrm{M}$ in DMSO under nitrogen atmosphere, irradiation time $=1 \mathrm{~h}$. ${ }^{b}$ Determined by GC using the internal standard method, error $5 \%$.

The reaction between 1a and $p$-methoxybenzenethiolate anion $\mathbf{2 b}$ was chosen as a model for the mechanistic studies. First, the addition of ET quenchers and radical scavengers were evaluated at low reaction conversion in order to assess the inhibition effect of such additives. In DMSO after 10 min of irradiation of a mixture of $1 \mathbf{a}$ and anion $\mathbf{2 b}, 44 \%$ of $4 \mathbf{b}$ was formed; the same result was observed in the dark (Table 2, entries 1 and 2). This last observation is not in agreement with an ET reaction since a catalytic effect of light is expected for this type of process. In relation to this, the photo-ejection from the excited arenethiolate anions to 1-iodoadamantane was previously proposed to trigger a non-chain $\mathrm{S}_{\mathrm{RN}} 1$ reaction leading to 1 -adamantyl aryl sulfide. The quantum yield for this photo-ejection ranges from 0.43 to 0.75 at $308 \mathrm{~nm}$ in $\mathrm{MeCN} .{ }^{10}$ 
The dark reaction was slightly inhibited in the presence of $40 \mathrm{~mol} \%$ of TEMPO and the yield of product $\mathbf{4} \mathbf{b}$ dropped to $37 \%$ (Table 2, entry 3 ). The addition of a strong electron acceptor was also evaluated; thus, a $20 \mathrm{~mol} \%$ of $p$-DNB reduced the amount of product $\mathbf{4 b}$. By increasing the amount of $p$-DNB up to $100 \mathrm{~mol} \%$, the formation of sulfide $\mathbf{4 b}$ was completely inhibited. However, in this condition a 100\% of 4-methoxyphenyl 4-nitrophenyl sulfide was found, arising from a nucleophilic aromatic substitution with one of the nitro substituents acting as a leaving group (Equation 6) (Table 2, entries 4 and 5). For this particular case, $p$-DNB competes with 1a as a better electrophile for a substitution reaction rather than a better electron acceptor. In order to avoid the aromatic substitution, $m$-DNB was chosen since, if the Meiseinheimer complex were formed, the latter would not be productive. ${ }^{11}$ Nevertheless, the use of a $100 \mathrm{~mol} \%$ of $m$-DNB had little or no effect on the formation of $\mathbf{4 b}$ (Table 2 , entry 6 ).

Table 2. Effect of additives and solvents in the reaction of neopentyl iodide 1a with $p$-methoxybenzenethiolate anion $\mathbf{2} \mathbf{b}^{\mathrm{a}}$

\begin{tabular}{|c|c|c|c|}
\hline Entry & Conditions & Additive & $\mathbf{4 b}(\%)^{b}$ \\
\hline 1 & $\mathrm{DMSO}, 25^{\circ} \mathrm{C}, 10 \mathrm{~min}, \mathrm{hv}$ & & 44 \\
\hline 2 & $\mathrm{DMSO}, 25^{\circ} \mathrm{C}, 10 \mathrm{~min}$, dark & & 44 \\
\hline 3 & $\mathrm{DMSO}, 25^{\circ} \mathrm{C}, 10 \mathrm{~min}$, dark & TEMPO $0.02 \mathrm{M}$ & 37 \\
\hline 4 & $\mathrm{DMSO}, 25^{\circ} \mathrm{C}, 10 \mathrm{~min}$, dark & $p$-DNB $0.01 \mathrm{M}$ & 33 \\
\hline 5 & DMSO, $25^{\circ} \mathrm{C}, 10 \mathrm{~min}$, dark & $p$-DNB $0.05 \mathrm{M}$ & $-{ }^{c}$ \\
\hline 6 & $\mathrm{DMSO}, 25^{\circ} \mathrm{C}, 10 \mathrm{~min}$, dark & $m$-DNB $0.05 \mathrm{M}$ & 39 \\
\hline $7^{\mathrm{d}}$ & $\mathrm{NH}_{3},-33{ }^{\circ} \mathrm{C}, 1 \mathrm{~h}, \mathrm{~h} v$ & & 50 \\
\hline $8^{\mathrm{d}}$ & $\mathrm{NH}_{3},-33{ }^{\circ} \mathrm{C}, 1 \mathrm{~h}$, dark & & - \\
\hline $9^{d}$ & $\mathrm{NH}_{3},-33^{\circ} \mathrm{C}, 1 \mathrm{~h}, \mathrm{~h} v$ & TEMPO $0.0018 \mathrm{M}$ & 27 \\
\hline $10^{\mathrm{d}}$ & $\mathrm{NH}_{3},-33^{\circ} \mathrm{C}, 1 \mathrm{~h}, \mathrm{hv}$ & $p$-DNB $0.0018 \mathrm{M}$ & - \\
\hline
\end{tabular}

${ }^{\mathrm{a}} \mathbf{1 a}=0.05 \mathrm{M}, p$-methoxybenzenethiolate anion $=0.05 \mathrm{M}$. ${ }^{\mathrm{b}}$ Determined by GC using the internal standard method, error $5 \% .{ }^{c} 100 \%$ of 4-methoxyphenyl 4-nitrophenyl sulfide was found. ${ }^{\mathrm{d}} \mathbf{1 a}=$ $0.008 \mathrm{M}, p$-methoxybenzenethiolate anion $=0.008 \mathrm{M}$.<smiles>O=[N+]([O-])C1C=CC([S-])C=C1</smiles>

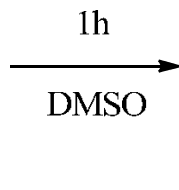<smiles>COc1ccc(Sc2ccc([N+](=O)[O-])cc2)cc1</smiles>

2b

Changing the solvent from DMSO to liquid ammonia the behavior of the reaction was completely different. Thus, after $1 \mathrm{~h}$ of irradiation a mixture of neopentyl iodide $\mathbf{1 a}$ and anion $\mathbf{2 b}$ rendered $50 \%$ yield of the substitution product $\mathbf{4 b}$ (Table 2, entry 7 ); there was no reaction in the dark and the yield of product $\mathbf{4 b}$ dropped significantly in the presence of both the radical trap 
TEMPO and the electron scavenger $p$-DNB (Table 2, entries 8, 9 and 10, respectively). All these results are in agreement with a $\mathrm{S}_{\mathrm{RN}} 1$ mechanism, where the neopentyl radical 8 is formed after a PET reaction from the $p$-methoxybenzenethiolate anion to iodide 1a (Equation 7). Radical 8 added to anion $\mathbf{2 b}$ to give radical anion $\mathbf{4} \mathbf{b}^{-}$(Equation 8), which is able to generate the substitution product $\mathbf{4 b}$ and neopentyl radical by dissociative ET to the neutral substrate (Equation 9).

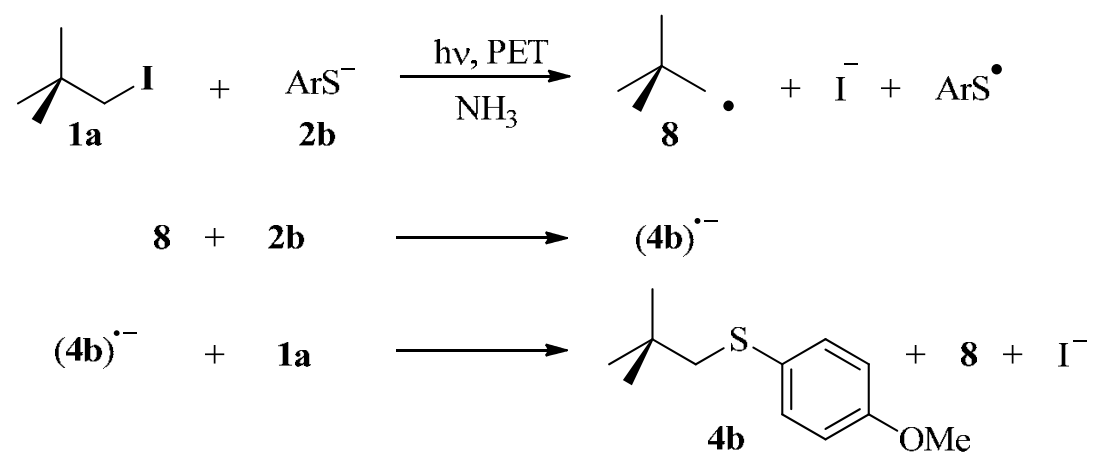

The results suggest that in DMSO, the reaction follows a polar mechanism with a minor, if any, contribution of a radical pathway. Another mechanistic possibility involves an initial dissociative ET within a solvent cage followed by coupling of the $\mathrm{R}^{\circ}$ radicals with $\mathrm{Nu}$ to give the substitution product by a geminate or cage collapse process (Scheme 1, path a).

A cage collapse mechanism has also been proposed in the substitution of neopentyl halides by alkylthiolate anions. The main evidence in favor of this mechanistic option involves no inhibition by the presence of radical or radical anion traps and the increase of reduction product by decreasing the solvent viscosity in the presence of good hydrogen donors such as DCHP, despite the fact that in some systems DCHP can also act as an anion trap. Moreover, the role of the radical of DCHP, formed after hydrogen donation, has not been clearly established, and in some cases it has been proposed as the initiator of a propagation cycle. ${ }^{4}$

On the other hand, when liquid ammonia is used as a solvent, the low temperature slows down the polar pathway and the ET path prevails under irradiation triggering a radical chain substitution reaction $\left(\mathrm{S}_{\mathrm{RN}} 1\right)$.

Despite the operating mechanism, the reaction conditions employing DMSO as solvent were selected to explore the reactivity and product distribution of dihalogenated neopentyl derivatives 1b-d. The selection of the solvent has been based on the simplicity of the procedure since reactions using liquid ammonia as solvent are not accessible in many organic chemistry laboratories.

\section{Reactions of arenethiolate anions (2) with 1,3-diiodo-2,2-dimethylpropane (1b)}

Dihalide $\mathbf{1 b}$ rendered exclusively disubstituted products 1,3-bis(arylthio)propanes 3 when the potassium tert-butoxide (tert-BuOK) was used in stoichiometric amounts for the in situ formation of the arenethiolate anions (Equation 10). After $1 \mathrm{~h}$ of reaction, dihalide $\mathbf{1 b}$ gave a 
$100 \%$ yield of disubstitution product 3a with benzenethiolate anion (Table 3, entry 1). Almost quantitative yields of products $\mathbf{3 b}$ and $\mathbf{3} \mathbf{c}$ were found for anions $\mathbf{2 b}$ and $\mathbf{2 c}$ (Table 3 , entries 3 and 4). The presence of small amounts of a monosubstitution halogenated product $5 \mathbf{c}$ in addition to 3c strongly suggests its participation as intermediate for the formation of the final product observed. Pyridinethiolate anions 2d showed the lower reactivity giving only $51 \%$ yield of product 3d (Table 3, entry 6).

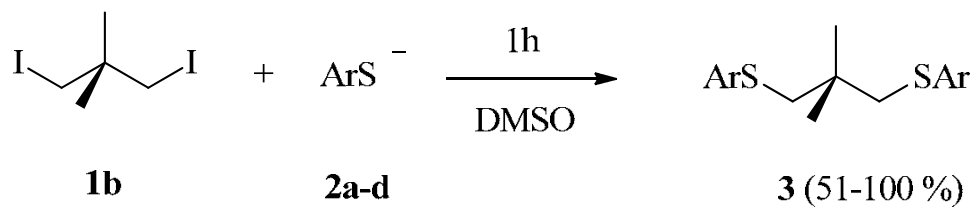

\section{Reactions of arenethiolate anions with 1,3-dibromo-2,2-dimethylpropane (1c)}

When dibromide 1c was allowed to react with arene thiolate anions, a mixture of disulfide products 3a-d, together with monosubstitution with retention of bromide 6a-d and cyclopropane derivatives 9a-d in low amounts, was found (Equation 11). Benezenethiolate anion afforded 17\% yield of 3a, 48\% yield of sulfide 6a and small amounts of 2,2-dimethylcyclopropyl phenyl sulfide 9a (Table 3 , entry 7). In the same conditions anion $\mathbf{2 b}$ gave a mixture of $\mathbf{3 b}$ and $\mathbf{6} \mathbf{b}$ in a 54 and 36\% yield, respectively (Table 3, entry 9). 2-Naphthalenethiolate anion 2c after $1 \mathrm{~h}$ of reaction with dibromoalkane afforded a mixture of disulfide 3c, 3-bromo-2,2-dimethylpropyl 2' naphthyl sulfide 6c and 2,2-dimethylcyclopropyl 2-naphthyl sulfide 9c in 15, 45 and 5\% yields, respectively (Table 3 , entry 10 ).

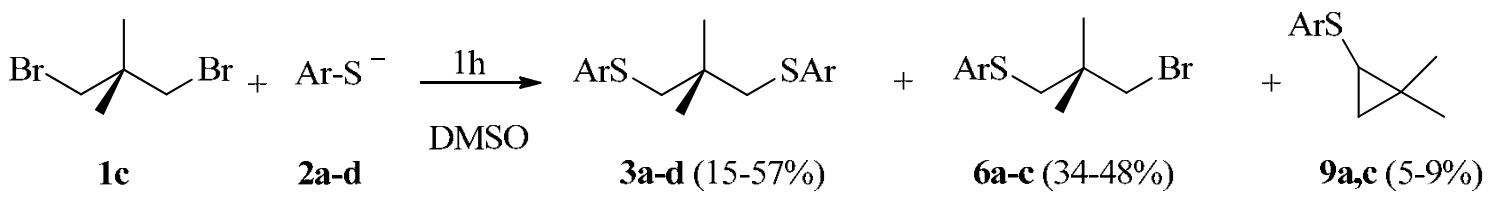

Finally, heterocyclic anion 2d afforded only product 3d in 20\% yield; as previously stated, this anion showed the lowest reactivity of the arenethiolate anions studied.

\section{Reactions of arenethiolate anions with 1-chloro-3-iodo-2,2-dimethylpropane (1d)}

The large difference in reactivity between iodide and chloride as leaving groups was evidenced in the reaction employing substrate 1d where, regardless of the nucleophile used, only the iodide was replaced by the arenethiolate anion with completed retention of the chloride atom. Benezenethiolate, $p$-methoxybenzenethiolate, 2-naphthalenethiolate and 2-pyridinethiolate anions gave aryl 3-chloro-2,2-dimethylpropyl sulfides 7a-d in 85, 100, 92 and 70\% yield, respectively (Equation 12, Table 3, entries 13, 15, 16 and 18). 


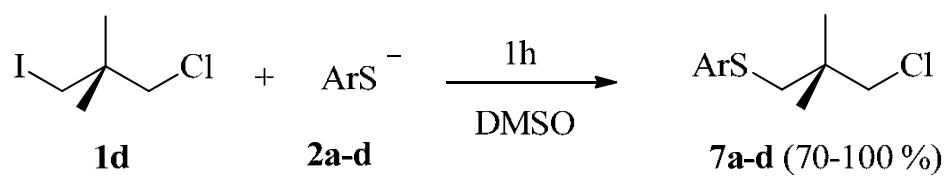

Table 3. Reactions of sulfur nucleophiles 2 with 1,3-dihalo-2,2-dimethylpropane in DMSO ${ }^{\mathrm{a}}$

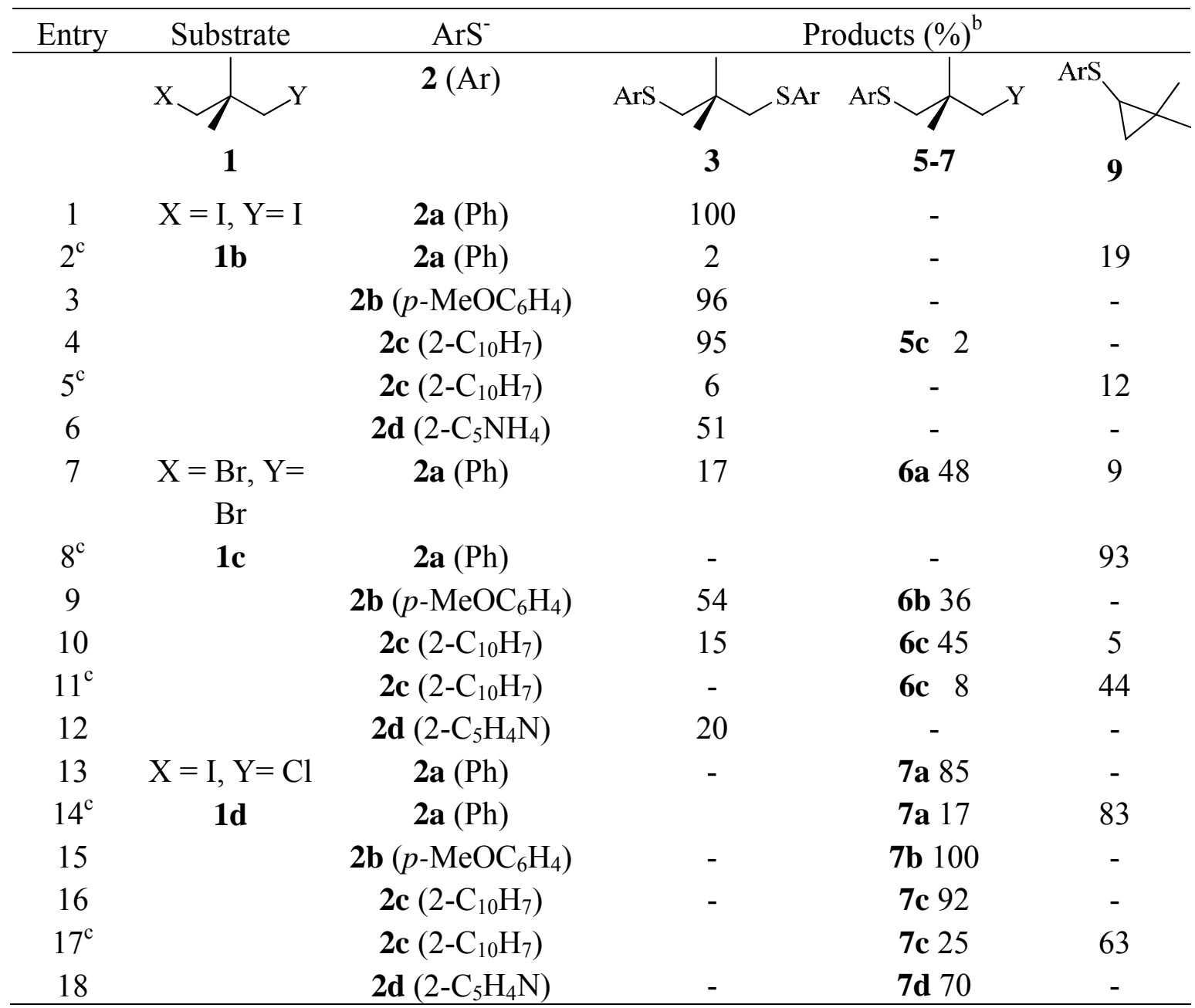

${ }^{\mathrm{a}}$ Substrate $=0.05 \mathrm{M}, \mathrm{ArS}^{-}=0.25 \mathrm{M}$ in DMSO, under laboratory light, the conversion was completed after $1 \mathrm{~h}$ reaction. ${ }^{\mathrm{b}}$ Determined by GC using the internal standard method, error $5 \%$. ${ }^{\mathrm{c}}$ In the presence of $0.25 \mathrm{M}$ of tert-BuOK.

\section{Development of aryl cyclopropyl sulfides (9a-c) in the reaction}

The formation of aryl cyclopropyl sulfides can be explained by deprotonation of the halomonosubstituted intermediates 5-7 followed by an intramolecular substitution reaction (Equations 13 and 14). Similar results were previously reported for 3-bromo-2,2-dimethylpropyl phenyl sulfone using $\mathrm{NaOEt}$ as a base (Equation 3); in this specific case, deprotonation was facilitated by the phenylsulfonyl group $\left(\mathrm{PhSO}_{2}\right) .{ }^{8}$ In order to support the mechanism proposed, 
the halo-monosubstituted compound was isolated and treated with a strong base. Particularly, 3iodo-2,2-dimethylpropyl 2-naphthyl sulfide 5c was isolated from the reaction between $\mathbf{1 b}$ and $\mathbf{2 c}$. When the latter iodo sulfide was treated with a five-molar excess of tert-BuOK in DMSO, cyclopropane derivative $\mathbf{9 c}$ was formed quantitatively (Equation 15).

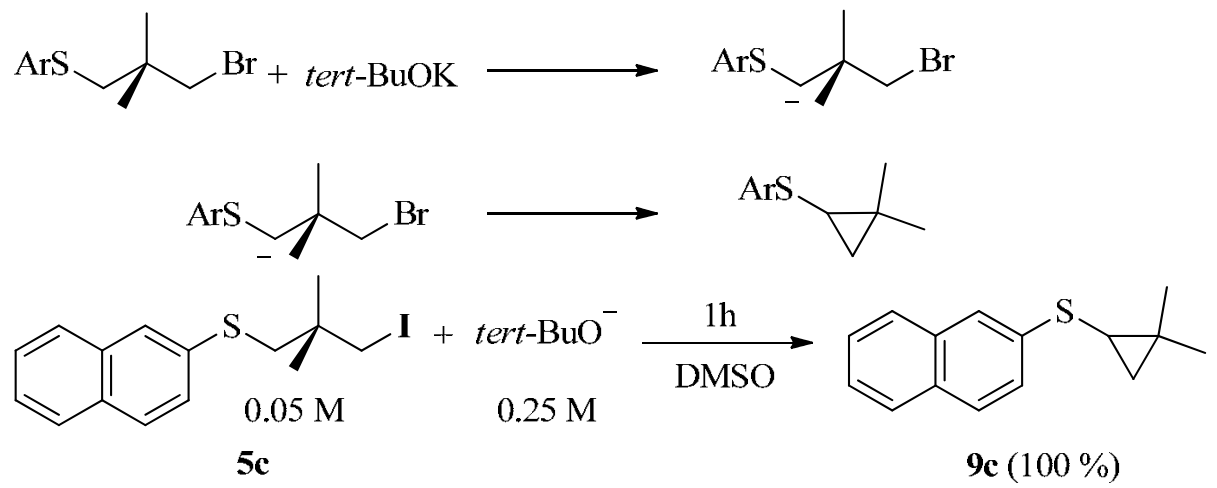

\section{Effect of the excess of tert-BuOK on the reactions}

It is worth mentioning that aryl cyclopropyl sulfides $\mathbf{9}$ are observed always in small amounts in the reactions of halides $\mathbf{1 b}$ and $\mathbf{1 c}$ with arenethiolate anions. Nevertheless, their formation can be avoided with the use of stoichiometric amounts of tert-BuOK. In addition, 2,2dimethylcyclopropyl 2-naphthyl sulfide 9c was obtained by deprotonation of the isolated aryliodo intermediate 5c (Equation 15). Taking these results into account, we evaluated the possibility of the selective synthesis of aryl cyclopropyl sulfides in a one-pot procedure.

When diiodoalkane $\mathbf{1 b}$ was treated with $0.25 \mathrm{M}$ of benzenethiolate anion $2 \mathbf{a}$ and $0.25 \mathrm{M}$ of tert-BuOK, cyclopropane 9a was obtained in very low yield (19\%), however, the formation of disulfide 3a (2\%) could not be suppressed (Table 3, entry 2). This result indicates that 3-iodo2,2-dimethylpropyl phenyl sulfide (5a, Y = I) is an intermediate in the reaction for the formation of 9a even we were not able to detect the presence of $\mathbf{5 a}$ from the reaction mixture (Scheme 2, path a). Furthermore, the second substitution affording 3 is as fast as the deprotonation followed by cyclization to yield 9 (Scheme 2, paths b and a, respectively). Although we succeeded in changing the product distribution to render 9a by adding an extra amount of tert-BuOK, the mass balance of this reaction was very poor. To check the stability of the substrate in the reaction media, a solution of $\mathbf{1 b}$ was stirred in the presence of $0.25 \mathrm{M}$ of tert-BuOK. After $1 \mathrm{~h}$, the substrate disappeared, leaving no detectable product by GC chromatography. This finding reveals that substrate $\mathbf{1 b}$ is not stable in such strong basic conditions. Similar results were found with 2-naphthalenethiolate anion $\mathbf{2 c}$ which, in the presence of $\mathbf{1 b}$ and with an extra amount of base, afforded the cyclopropane derivative $9 \mathrm{c}$ in only a $12 \%$ and the disulfide $3 \mathrm{c}$ in $6 \%$ yields (Table 3, entry 5). As a result, using substrate 1,3-diiodo-2,2-dimethylpropane, the reaction was not selective with a low mass balance due to the instability of the alkyl diodide and the fast second substitution reaction. This withdraw can be solved by two approaches, namely, decreasing the rate of the second substitution by reducing the nucleophile concentration or by 
changing the leaving group. Regarding the second alternative, dibromide 1c was selected. By mixing 1,3-dibromo-2,2-dimethylpropane 1c with anion 2a and tert-BuOK in the same concentration, 93\% yield of the desired cyclopropane derivative 9a was found (Table 3, entry 8). The naphthyl cyclopropyl thioderivative 9c was obtained in a $44 \%$ yield together with a remaining $8 \%$ of the monosubstituted compound with retention of one bromide atom $6 \mathbf{c}(\mathrm{Y}=\mathrm{Br})$ (Table 3, entry 11). Neither $\mathrm{PhS}^{-}$nor $2-\mathrm{C}_{10} \mathrm{H}_{7} \mathrm{~S}^{-}$afforded disulfides $3 \mathbf{a}$ and $3 \mathbf{c}$ in the presence of an excess of tert-BuOK. These results clearly point out that cyclization can be selectively obtained by delaying the second substitution, changing the second leaving group. In this condition deprotonation is faster and aryl cyclopropyl sulfides are formed in very good yields (Scheme 2, exclusive path a). This procedure can be extended to iodo chloro derivative 1d affording cyclic compounds 9a and 9c in 89 and $63 \%$ yields with $\mathrm{PhS}^{-}$and $2-\mathrm{C}_{10} \mathrm{H}_{7} \mathrm{~S}^{-}$anions respectively (Table 3 , entries 14 and 17).

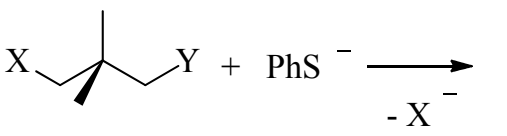

1b, $\mathrm{X}=\mathrm{Y}=\mathrm{I}$

1c, $\mathrm{X}=\mathrm{Y}=\mathrm{Br}$

1d, $\mathrm{X}=\mathrm{I}, \mathrm{Y}=\mathrm{Cl}$

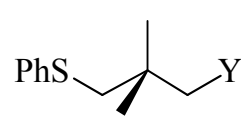

5a, $\mathrm{Y}=\mathrm{I}$

6a, $\mathrm{Y}=\mathrm{Br}$

$7 \mathrm{a}, \mathrm{Y}=\mathrm{Cl}$
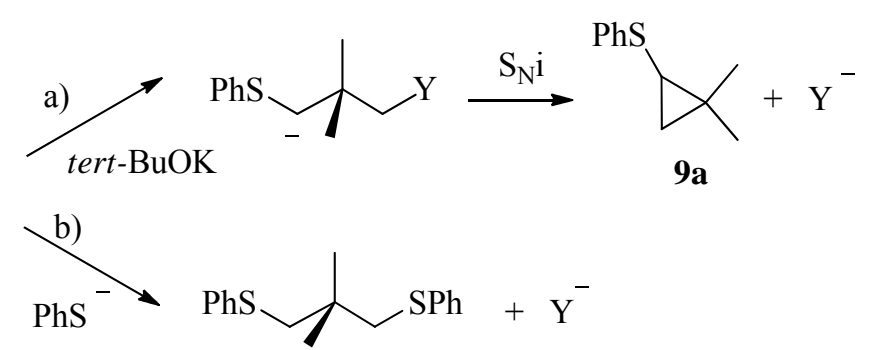

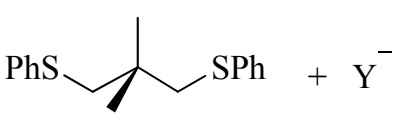

3a

\section{Scheme 2}

\section{Conclusions}

The synthetic scope of the reactions between mono- and di-haloneopentyl derivatives with benzenethiolate 2a, 4-methoxybenzenethiolate 2b, 2-naphthalenethiolate $\mathbf{2 c}$, and 2pyridinethiolate $\mathbf{2 d}$ anions has been established and the results are summarized as follows:

Neopentyl iodide 1a reacted with thiolate anions 2a-d to afford the corresponding substitution products from moderate to excellent yields (68-96\%). Based on non-kinetic evidence, the mechanism for these reactions goes from $\mathrm{S}_{\mathrm{RN}} 1$ to polar $\mathrm{S}_{\mathrm{N}} 2$ by changing the solvent from $\mathrm{NH}_{3}$ to DMSO, respectively.

1,3-Diiodo-2,2-dimethylpropane $\mathbf{1 b}$ gave disubstitution products 3a-c with thiolate anions 2a-c in excellent yields (95-100\%) and with anion 2d, disulfide 3d was obtained in moderate yield (51\%).

After reaction with thiolate anions 2a-d, 1,3-dibromo-2,2-dimethylpropane 1c rendered a mixture of disubstitution products 3a-d (15-54\%) and monosubstituted derivatives with retention of one bromide atom 6a-c (36-48\%), whereas 1-chloro-3-iodo-2,2-dimethylpropane 1d afforded exclusively mono-halosubstituted derivatives 7a-d in good yields (70-100\%). 
Finally, it was possible to synthesize novel aryl cyclopropyl sulfides 9a,c in good yields (4493\%) when the reactions between 1c-d and thiolate anions 2a,c were performed in the presence of an excess of tert-BuOK.

\section{Experimental Section}

General. ${ }^{1} \mathrm{H}$ and ${ }^{13} \mathrm{C}$ NMR spectra were recorded at 400.16 and $100.62 \mathrm{MHz}$ respectively on a Bruker Advance II - 400 spectrometer, and all spectra are reported in $\delta(\mathrm{ppm})$ relative to $\mathrm{Me}_{4} \mathrm{Si}$, with $\mathrm{CDCl}_{3}$ as solvent. Gas chromatographic analyses were performed on a Hewlett Packard 6890 A with a flame-ionization detector, on a HP-5 $30 \mathrm{~m}$ capillary column of a $0.32 \mathrm{~mm} \times 0.25$ mm film thickness. Mass spectra were performed on a Shimadzu GC-MS QP 5050 spectrometer. HRMS spectra were recorded on a Bruker, MicroTOF Q II equipment, operated with an ESI source operated in (positive/ negative) mode, using nitrogen as nebulizing and drying gas and sodium formiate $10 \mathrm{mM}$ as internal calibrant.

Materials. tert-BuOK, benzenethiol, p-methoxybenzenethiol, 2-naphthalenethiol, 2pyridinethiol, neopentyl iodide, $p$-dinitrobenzene, $m$-dinitrobenzene and DTBN were all highpurity commercial samples used without further purification. DMSO was distilled under vacuum and stored over molecular sieves $(4 \AA)$. Arenethiolate anions ( $\left.\mathrm{ArS}^{-}\right)$were generated in situ by deprotonation using tert-BuOK. The 1,3-dihalo-2,2-dimethylpropanes 1b-d, were synthesized following the procedures previously reported. ${ }^{12}$

Neopentyl phenyl sulfide, $\mathbf{4 a} ;{ }^{2}$ p-methoxyphenyl neopentyl sulfide, 4b; neopentyl 2-pyridyl sulfide, 4d $;^{13}$ 2,2-dimethyl-1,3-bis(phenylthio)propane, 3a; ${ }^{7}$ 3-bromo-2,2-dimethylpropyl phenyl sulfide, 6a; ${ }^{7}$ 3-chloro-2,2-dimethylpropyl phenyl sulfide, $\mathbf{7 a}^{7}$ and 2,2-dimethylcyclo-propyl phenyl sulfide $9 \mathbf{a}^{14}$ are known and exhibited physical properties identical to those reported in the literature. They were also isolated by radial chromatography on silica gel 60 containing gypsum from the reaction mixture and characterized by ${ }^{1} \mathrm{H}$ and ${ }^{13} \mathrm{C}$ NMR and mass spectrometry.

\section{Reactions of anions ArS ${ }^{-}$with neopentyl halides. General procedure}

The reaction was carried out in a three-necked, $10 \mathrm{~mL}$ Schlenk tube equipped with a nitrogen gas inlet and a magnetic stirrer. The flask was dried under vacuum, filled with nitrogen and then charged with $10 \mathrm{~mL}$ of dried DMSO. Then $2.5 \mathrm{mmol}$ of tert-BuOK, $2.5 \mathrm{mmol}$ of the nucleophile and $0.5 \mathrm{mmol}$ of substrate were added to the degassed solvent under nitrogen. After $1 \mathrm{~h}$ of irradiation with a high pressure Hg lamp or under laboratory light, the reaction was quenched by the addition of MeI ( 6 equiv) in excess and poured in $30 \mathrm{~mL}$ of water, and then the mixture was extracted with methylene chloride $(3 \times 20 \mathrm{~mL})$. The organic extract was washed twice with water, dried and the products were quantified by GC with diphenyl disulfide or cinnamyl phenyl sulfide as internal standard. 
Reactions of anion (2c) with neopentyl iodide (1a) in liquid ammonia. The following procedure is representative of these reactions. $p$ - $\mathrm{MeOC}_{6} \mathrm{H}_{4} \mathrm{SH}(1 \mathrm{mmol})$ and tert-BuOK (1.01 $\mathrm{mmol}$ ) were added to $125 \mathrm{~mL}$ of distilled ammonia; after $10 \mathrm{~min}$ the substrate neopentyl iodide ( $1 \mathrm{mmol}$ ) was added to the solution and the reaction mixture irradiated for $1 \mathrm{~h}$. Next, the reaction was quenched with an excess of MeI (6 equiv) and the ammonia allowed to evaporate. The residue was dissolved in water and then extracted with methylene chloride $(3 \times 20 \mathrm{~mL})$, the products were quantified by GC using the internal standard method as indicated above.

2-Naphthyl neopentyl sulfide (4c). Isolated by radial chromatography techniques with petroleum ether as eluent from the crude product reaction mixture of anion $\mathbf{2 c}$ and 1a. Colorless solid, mp 122-125 ${ }^{\circ} \mathrm{C} .{ }^{1} \mathrm{H}$ NMR: $\delta 1.05$ (s, 9H), 2.96 (s, 2H), 7.34-7.42 (m, 3H), 7.65-7.71 (m, $4 \mathrm{H}) ;{ }^{13} \mathrm{C}$ NMR: $\delta 29.1,32.6,48.3,125.7,126.3,126.6,126.8,127.5,127.8,129.0,132.5,133.5$, 134.3; MS: 230 (M+, 73\%), 215 (2), 173 (44), 160 (100), 129 (17), 115 (41), 57 (19); HRMS (ESI) for $\mathrm{C}_{15} \mathrm{H}_{18} \mathrm{~S}[\mathrm{M}]^{+}$calcd: 231.1202; found: 231.1198 .

1,3-Bis(4-methoxybenzenethio)-2,2-dimethylpropane (3b). Was isolated as oil by radial chromatography techniques with petroleum ether/diethyl ether (90:10) as eluent from the crude product reaction mixture of anion $2 \mathbf{b}$ and 1b. ${ }^{1} \mathrm{H}$ NMR: $\delta 1.07(\mathrm{~s}, 6 \mathrm{H}), 2.96(\mathrm{~s}, 4 \mathrm{H}), 3.78(\mathrm{~s}, 6 \mathrm{H})$, $6.81(\mathrm{~d}, 4 \mathrm{H}, 8.8 \mathrm{~Hz}), 7.33$ (d, 4H, $8.8 \mathrm{~Hz}) .{ }^{13} \mathrm{C}$ NMR: $\delta$ 26.6, 37.2, 48.1, 55.3, 114.5, 128.1, 132.8, 158.6; MS: 348 (M+, 52\%), 209 (51), 195 (17), 153 (46), 140 (22), 139 (100), 109 (14); HRMS (ESI) for $\mathrm{C}_{19} \mathrm{H}_{24} \mathrm{NaO}_{2} \mathrm{~S}_{2}[\mathrm{M}+\mathrm{Na}]^{+}$calcd: 371.1110 ; found: 371.1159 .

1,3-Bis(2-naphthylthio)-2,2-dimethylpropane (3c). Was isolated by radial chromatography techniques with petroleum ether/diethyl ether (90:10) as eluent from the crude product reaction mixture of anion 2c and 1b. White solid, mp 99-101 ${ }^{\circ} \mathrm{C} .{ }^{1} \mathrm{H}$ NMR: $\delta 1.19$ (s, 6H), 3.17 (4H, s), 7.37-7.43 (m, 6H), 7.62-7.75 (m, 8H); ${ }^{13} \mathrm{C}$ NMR: $\delta 26.9,37.2,45.7,125.5,126.5,126.8,127.0$, 127.6, 127.7, 128.3, 131.7, 133.8, 135.1; MS: 388 (M+100\%), 387 (85), 229 (61), 215 (51), 173 (71), 159 (55), 115 (37); HRMS (ESI) for $\mathrm{C}_{25} \mathrm{H}_{24} \mathrm{NaS}_{2}[\mathrm{M}+\mathrm{Na}]^{+}$calcd: 411.1212; found: 411.1214.

1,3-Bis(2-pyridylthio)-2,2-dimethylpropane (3d). Was isolated as oil by radial chromatography techniques with petroleum ether/diethyl ether (90:10) as eluent from the crude product reaction mixture of anion 2d and 1b. ${ }^{1} \mathrm{H}$ NMR: $\delta 1.12(\mathrm{~s}, 6 \mathrm{H}), 3.38(\mathrm{~s}, 4 \mathrm{H}), 6.94$ (ddd, 2H, $0.8 \mathrm{~Hz}, 5.2 \mathrm{~Hz}, 6.0 \mathrm{~Hz}$ ), 7.19 (d, 2H, 8.0 Hz), 7.43 (dt, 2H, $1.6 \mathrm{~Hz}, 8.0 \mathrm{~Hz}$ ), 8.39 (d, 2H, 0.8 $\mathrm{Hz}){ }^{13} \mathrm{C}$ NMR: $\delta$ 26.3, 36.3, 40.7, 119.3, 122.42, 135.8, 149.2, 159.3; MS: 243 (23\%), 212 (6), 180 (79), 179 (68), 166 (78), 164 (26), 136 (21), 125 (21), 124 (43), 111 (39), 112 (100), 78 (71), 67 (18), 55 (28). HRMS (ESI) for $\mathrm{C}_{15} \mathrm{H}_{18} \mathrm{~N}_{2} \mathrm{~S}_{2}$ [M+H] $]^{+}$calcd: 291.0984; found: 291.1002.

3-Iodo-2,2-dimethylpropyl 2-naphthyl sulfide (5c). Was isolated as oil by radial chromatography techniques with petroleum ether/diethyl ether (90:10) as eluent from the crude product reaction mixture of anion $2 \mathrm{c}$ and 1b. ${ }^{1} \mathrm{H}$ NMR $\left(400.16 \mathrm{MHz}, \mathrm{CDCl}_{3}\right): \delta 1.17(\mathrm{~s}, 6 \mathrm{H})$, $3.10(\mathrm{~s}, 2 \mathrm{H}), 3.31(\mathrm{~s}, 2 \mathrm{H}), 7.38-7.47(\mathrm{~m}, 3 \mathrm{H}), 7.71-7.79(\mathrm{~m}, 4 \mathrm{H}) ;{ }^{13} \mathrm{C} \mathrm{NMR}: \delta 22.2,26.7,35.7$, 45.8, 125.8, 126.6, 127.1, 127.4, 127.7, 127.8, 128.5, 131.8, 133.8, 134.7; MS: $356\left(\mathrm{M}^{+}, 45 \%\right)$, 229 (16), 173 (100), 159 (13), 129 (22). HRMS (ESI) for $\mathrm{C}_{15} \mathrm{H}_{17} \mathrm{~S}$ [M-I] ${ }^{+}$calcd: 229.1045 found: 229.1044. 
3-Bromo-2,2-dimethylpropyl 4-methoxyphenyl sulfide (6b). Was isolated as oil by radial chromatography techniques with petroleum ether/diethyl ether (90:10) as eluent from the crude product reaction mixture of anion $2 \mathbf{b}$ and 1c. ${ }^{1} \mathrm{H}$ NMR: $\delta 1.10(\mathrm{~s}, 6 \mathrm{H}), 2.95(\mathrm{~s}, 2 \mathrm{H}), 3.43(\mathrm{~s}, 2 \mathrm{H})$, $3.79(\mathrm{~s}, 3 \mathrm{H}), 6.83(\mathrm{~d}, 2 \mathrm{H}, 8.8 \mathrm{~Hz}) .7 .39(\mathrm{~d}, 2 \mathrm{H}, 8.8 \mathrm{~Hz}) ;{ }^{13} \mathrm{C} \mathrm{NMR}: \delta 25.7,36.7,44.9,47.2,55.4$, 114.6, 127.6, 130.2, 133.3, 158.9; MS: $290\left(\mathrm{M}^{+}, 43 \%\right), 288\left(\mathrm{M}^{+}, 50\right), 153$ (100), $140(41), 139$ (42), 138 (31), 109 (34), 107 (28), 69 (14), 55 (12).

3-Bromo-2,2-dimethylpropyl 2-naphthyl sulfide (6c). Was isolated as oil by radial chromatography techniques with petroleum ether/diethyl ether (90:10) as eluent from the crude product reaction mixture of anion 2c and 1c. ${ }^{1} \mathrm{H}$ NMR: $\delta 1.15(\mathrm{~s}, 6 \mathrm{H}), 3.13(\mathrm{~s}, 2 \mathrm{H}), 3.47(\mathrm{~s}, 2 \mathrm{H})$, 7.40-7.47 (m, 3H), 7.72-7.80 (m, 4H); ${ }^{13} \mathrm{C}$ NMR: $\delta 25.8,36.7,44.6,44.8,125.7,126.6,127.1$, 127.4, 127.7, 127.8, 128.5, 131.8, 133.8, 134.7; MS: $310\left(\mathrm{M}^{+}, 27 \%\right), 308\left(\mathrm{M}^{+}, 27\right), 173(100)$, 160 (19), 129 (20), 115 (29); HRMS (ESI) for $\mathrm{C}_{15} \mathrm{H}_{18} \mathrm{BrS}[\mathrm{M}+\mathrm{H}]^{+}$calcd: 309.0307, found: 309.0302 .

3-Chloro-2,2-dimethylpropyl 4-methoxyphenyl sulfide (7b). Was isolated as oil by radial chromatography techniques with petroleum ether/diethyl ether (90:10) as eluent from the crude product reaction mixture of anion $2 \mathbf{b}$ and 1d. ${ }^{1} \mathrm{H}$ NMR: $\delta 1.08(\mathrm{~s}, 6 \mathrm{H}), 2.95(\mathrm{~s}, 2 \mathrm{H}), 3.51(\mathrm{~s}, 2 \mathrm{H})$, 3.79 (s, 3H), 6.85 (d, 2H, $8.8 \mathrm{~Hz}), 7.39$ (d, 2H, 8.8 Hz); ${ }^{13} \mathrm{C}$ NMR: $\delta 25.0,37.4,46.4,54.1,55.3$, 114.8, 127.7, 133.2, 158.8; MS: $246\left(\mathrm{M}^{+}, 31 \%\right), 244\left(\mathrm{M}^{+}, 73\right), 188$ (18), 153 (100), 140 (62), 139 (48), 138 (32), 125 (21), 109 (34), 107 (28); HRMS (ESI) for $\mathrm{C}_{12} \mathrm{H}_{18} \mathrm{ClOS}[\mathrm{M}+\mathrm{H}]^{+}$calcd: 245.0761; found: 245.0819 .

3-Chloro-2,2-dimethylpropyl 2-naphthyl sulfide (7c). Was isolated as oil by radial chromatography techniques with petroleum ether/diethyl ether (90:10) as eluent from the crude product reaction mixture of anion 2c and 1d. ${ }^{1} \mathrm{H}$ NMR: $\delta 1.18(\mathrm{~s}, 6 \mathrm{H}), 3.19(\mathrm{~s}, 2 \mathrm{H}), 3.59(\mathrm{~s}, 2 \mathrm{H})$, 7.48-7.54 (m, 3H), 7.78-7.87 (m, 4H); ${ }^{13} \mathrm{C}$ NMR: $\delta 25.2,37.4,43.9,54.2,125.8,126.7,127.2$, 127.3, 127.8, 127.8, 128.5, 131.8, 133.9, 134.9; MS: $266\left(\mathrm{M}^{+}, 30 \%\right), 264\left(\mathrm{M}^{+}, 68\right), 208(26), 173$ (100), 160 (52), 129 (38), 128 (22), 115 (54); HRMS (ESI) for $\mathrm{C}_{15} \mathrm{H}_{18} \mathrm{ClS}[\mathrm{M}+\mathrm{H}]^{+}$calcd: 265.0812, found: 265.0810 .

3-Chloro-2,2-dimethylpropyl 2-pyridyl sulfide (7d). Was isolated as oil by radial chromatography techniques with petroleum ether/diethyl ether (90:10) as eluent from the crude product reaction mixture of anion 2d and 1d. ${ }^{1} \mathrm{H}$ NMR: $\delta 1.09(\mathrm{~s}, 6 \mathrm{H}), 3.36(\mathrm{~s}, 2 \mathrm{H}), 3.49(\mathrm{~s}, 2 \mathrm{H})$, 6.96 (dd, 1H, 5.2 Hz, $6.8 \mathrm{~Hz}), 7.20$ (d, 1H, 8 Hz), 7.39 (dt, 1H, 1.7 Hz, 7.7 Hz), 8.40 (d, 1H, 4.4 $\mathrm{Hz}) ;{ }^{13} \mathrm{C}$ NMR: $\delta$ 24.8, 36.9, 38.6, 54.4, 119.5, 122.5, 135.9, 149.2, 158.7; MS: $215\left(\mathrm{M}^{+}, 22 \%\right)$, 200 (7), 166 (74), 125 (71), 124 (100), 112 (30), 111 (30), 79 (38), 78 (63), 67 (26), 55 (27), 51 (27).

2,2-Dimethylcyclopropyl 2-naphthyl sulfide (9c). Was isolated as oil by radial chromatography techniques with petroleum ether as eluent from the crude product reaction mixture of anion 2c and 1c, in the presence of $0.25 \mathrm{M}$ excesses of tert-BuOK. ${ }^{1} \mathrm{H}$ NMR: $\delta 0.58(\mathrm{t}, 1 \mathrm{H}, 4.8 \mathrm{~Hz}), 1.03$ $(\mathrm{dd}, 1 \mathrm{H}, 4.8 \mathrm{~Hz}, 8.4 \mathrm{~Hz}), 1.22(\mathrm{~s}, 3 \mathrm{H}), 1.33(\mathrm{~s}, 3 \mathrm{H}), 2.16(\mathrm{dd}, 1 \mathrm{H}, 4.8 \mathrm{~Hz}, 8.4 \mathrm{~Hz}), 7.36-7.45$ (m, $3 \mathrm{H})$, 7.67-7.78 (m, 4H) ${ }^{13} \mathrm{C}$ NMR: $\delta$ 20.0, 20.1, 21.3, 25.8, 26.5, 123.0, 125.0, 126.5, 126.8, 
127.8, 128.1, 131.2, 133.9, 137.1; MS: $228\left(\mathrm{M}^{+}, 77 \%\right), 172$ (100), 128 (22); HRMS (ESI) for $\mathrm{C}_{15} \mathrm{H}_{17} \mathrm{~S}[\mathrm{M}+\mathrm{H}]^{+}$calcd: 229.1045; found: 229.1040 .

\section{Acknowledgements}

This work was supported partly by SECyT-UNC, CONICET and FONCYT, Argentina. C. A. B. gratefully acknowledges the receipt of a fellowship from CONICET.

\section{References}

1. (a) Rossi, R. A.; Pierini, A. B.; Peñéñory, A. B. Chem. Rev. 2003, 103, 71. (b) Pierini, A. B.; Peñéñory, A. B. Baumgartner, M. T. In Electron Transfer Reactions in Organic Synthesis; Vanelle, P. Ed., Research Signpost: Trivandrum, 2002, p 63. (c) Rossi, R. A.; Pierini, A. B.; Santiago, A. N. In Organic Reactions; Paquette, L. A., Bittman, R. Eds.; John Wiley \& Sons Inc: New York, 1999; Vol. 54, Chapter 1, p 1. (d) Rossi, R. A.; Peñéñory, A. B. In CRC Handbook of Organic Photochemistry and Photobiology, Horspool, W. M.; Lenci, F., Eds.; 2nd Edn.; CRC Press Inc.: Boca Raton, 2003; Chapter 47, p 47. (e) Savéant, J. M. Acc. Chem. Res. 1993, 26, 455. (f) Kornblum, N. Aldrichim. Acta 1990, 23, 71.

2. Pierini, A. B.; Peñéñory, A. B.; Rossi, R. A. J. Org. Chem. 1985, 50, 2739.

3. Beckwith, A. L. J.; Palacios, S. M. J. Phys. Org. Chem. 1991, 4, 404.

4. Ashby, E. C.; Park, W. S.; Goel, A. B.; Su, W. Y. J. Org. Chem.1985, 50, 5184.

5. Ashby, E. C.; Argyropoulos, J. N. J. Org. Chem. 1985, 50, 3274.

6. Peñéñory, A. B.; Rossi, R. A. Gazz. Chim. Ital. 1995, 125, 605.

7. Issari, B.; Stirling, C. J. M. J. Chem. Soc. Perkin Trans. 2 1984, 6, 1043.

8. Masuda, T.; Numata, T.; Furukawa, N.; Oae, S. J. Chem. Soc., Perkin Trans. 2 1978, 12, 1302.

9. (a) Lukach, A. E.; Santiago, A. N.; Rossi, R. A. J. Phys. Org. Chem. 1994, 7, 610. (b) Lukach, A. E.; Santiago, A. N.; Rossi, R. A. J. Org. Chem. 1997, 62, 4262. (c) Lukach, A. E.; Rossi, R. A. J. Org. Chem. 1999, 64, 5826.

10. Ahbala, M.; Hapiot, P.; Houmam, A.; Jouini, M.; Pinson, J.; Savéant, J-M. J. Am. Chem. Soc 1995, 117, 11488.

11. Terrier, F. Chem. Rev. 1982, 82, 77.

12. Argüello, J. E.; Peñéñory, A. B. J. Org. Chem. 2003, 68, 2362.

13. Barton, D. H. R.; Crich, D.; Motherwell, W. B. J. Chem. Soc., Chem. Comm. 1983, 17, 939.

14. Masuda, T.; Furukawa, N.; Oae, S. Bull. Chem. Soc. Japan 1978, 51, 2659. 